\title{
Field observations of soil hydrological flow path evolution over 10 millennia
}

\author{
Anne Hartmann ${ }^{1}$, Ekaterina Semenova ${ }^{2}$, Markus Weiler ${ }^{2}$, and Theresa Blume ${ }^{1}$ \\ ${ }^{1}$ Section Hydrology, GFZ German Research Centre for Geosciences, Potsdam, Germany \\ ${ }^{2}$ Chair of Hydrology, University of Freiburg, Freiburg, Germany \\ Correspondence: Anne Hartmann (aha@gfz-potsdam.de)
}

Received: 20 January 2020 - Discussion started: 24 January 2020

Revised: 18 April 2020 - Accepted: 17 May 2020 - Published: 25 June 2020

\begin{abstract}
Preferential flow strongly controls water flow and transport in soils. It is ubiquitous but difficult to characterize and predict. This study addresses the occurrence and the evolution of preferential flow during the evolution of landscapes and here specifically during the evolution of hillslopes. We targeted a chronosequence of glacial moraines in the Swiss Alps to investigate how water flow paths evolve along with the soil-forming processes. Dye tracer irrigation experiments with a Brilliant Blue FCF solution $\left(4 \mathrm{~g} \mathrm{~L}^{-1}\right)$ were conducted on four moraines of different ages $(30,160$, 3000 , and 10000 years). At each moraine, three dye tracer experiments were conducted on plots of $1.5 \mathrm{~m} \times 1.0 \mathrm{~m}$. The three plots at each moraine were characterized by different vegetation complexities (low, medium, and high). Each plot was further divided into three equal subplots for the application of three different irrigation amounts $(20,40$, and $60 \mathrm{~mm}$ ) with an average irrigation intensity of $20 \mathrm{~mm} \mathrm{~h}^{-1}$. The day after the experiment five vertical soil sections were excavated, and the stained flow paths were photographed. Digital image analysis was used to derive average infiltration depths and flow path characteristics such as the volume and surface density of the dye patterns. Based on the volume density, the observed dye patterns were assigned to specific flow type categories. The results show a significant change in the type of preferential flow paths along the chronosequence. The flow types change from a rather homogeneous matrix flow in coarse material with high conductivities and a sparse vegetation cover at the youngest moraine to a heterogeneous infiltration pattern at the medium-age moraines. Heterogeneous matrix and finger flow are dominant at these intermediate age classes. At the oldest moraine only macropore flow via root channels was observed in deeper parts of
\end{abstract}

the soil, in combination with a very high water storage capacity of the organic top layer and low hydraulic conductivity of the deeper soil. In general, we found an increase in water storage with increasing age of the moraines, based on our observations of the reduction in infiltration depth as well as laboratory measurements of porosity. Preferential flow is, however, not only caused by macropores, but especially for the medium-age moraine, it seems to be mainly initiated by soil surface characteristics (vegetation patches and microtopography).

\section{Introduction}

The ability of soil to store and to transport water is essential for its ecosystem services such as nutrient cycling or water and gas balances (Clothier et al., 2008; Amundson et al., 2015; Hatfield et al., 2017; Shang et al., 2018). Thus, the interaction of water and soil is an elementary foundation for the existence and functioning of terrestrial ecosystems. This interaction is part of a large network of interactions of various ecosystem components (flora, fauna, material and energy fluxes, geomorphological conditions, and climate), which are also necessary for the existence and functioning of ecosystems. Soil filters the percolating water, redistributes it to groundwater or stream water, or holds it against gravity and makes it available for plants.

The soil functions are influenced and controlled by soil properties, which can vary spatially on the small (Hu et al., 2008) and large scales (vertically along the profile and horizontally across landscapes; Bevington et al., 2016), as well as temporally. These properties include soil texture and struc- 
ture, i.e., the pore and grain size distributions, which in turn control the storage and transport capacity of the soil. Additional factors influencing soil functions are climate, topography, and vegetation. In undisturbed natural systems these factors are usually assumed to be constant at the observational timescale, and the inherent system dynamics only become apparent on long timescales.

Preferential flow, which is defined according to Hendrickx and Flury (2001) as a phenomenon "where water and solutes move along certain pathways, while bypassing a fraction of the porous matrix", has impacts on water storage (Rye and Smettem, 2017) and thus plant water availability. It furthermore affects the transport of nutrients and contaminants (Jarvis, 2007) throughout the vadose zone and consequently also soil chemistry (Jin and Brantley, 2011; Bundt et al., 2000) and groundwater quality. Allaire et al. (2009) attribute rapid flow and mass transport to flow through earthworm burrows, cracks in soil, and flow paths resulting from soil layering and hydrophobicity. They defined four types of preferential flow: crack flow, burrow flow (created by soil fauna), finger flow, and lateral flow along layer interfaces, where flow in burrows and cracks is also often classified as macropore flow. We will in the following distinguish flow in macropores according to their origin as crack flow and biopore flow, where the latter includes channels by activities of roots and soil fauna. Preferential flow in the form of macropore flow occurs mostly in fine-textured soils, whereas finger and funnel flow rather occurs in soils with a coarse texture (Hendrickx and Flury, 2001). General factors which can cause preferential flow paths are surface structure and properties such as vegetation cover, microtopography or hydrophobicity, as well as subsurface soil properties such as soil structure and soil type, subsurface heterogeneities, flow instabilities, and plant root activities (Weiler and Naef, 2003; Clothier et al., 2008; Bachmair et al., 2009; Jarvis, 2007; van Schaik, 2009; Wang et al., 2018). Soil water conditions were also found to have an influence on the preferential flow path characteristics (Gimbel et al., 2016; Hardie et al., 2011; Bogner et al., 2008).

Many preferential flow-influencing properties such as soil structure, soil texture, or vegetation cover change during landscape evolution (e.g., Vilmundardóttir et al., 2014; Egli et al., 2010; Dümig et al., 2011) and thus also lead to a change in the soil hydraulic behavior (Lohse and Dietrich, 2005), which in turn has a direct impact on the surface and subsurface water transport. We therefore assume that the age of the soil has an influence on the prevailing preferential flow paths and thus the type and also the depth extent of the preferential flow paths can change over time. Especially root activities can lead to the generation of preferential flow paths in deeper layers, which was found by Cheng et al. (2014) based on a comparison of young and older forest plantations. On a large timescale of several million years, Lohse and Dietrich (2005) found a transition from mainly vertical water transport in younger volcanic soils in the Hawaiian Islands to lateral water transport along the boundary of a subsurface clay layer. The younger soil was coarse textured with high saturated hydraulic conductivities along the profile and a rather low field capacity, whereas the older soil revealed a higher field capacity and a distinct reduction in saturated hydraulic conductivity throughout the profile due to clay accumulation. Yoshida and Troch (2016) observed a major change in flow paths from deep groundwater flow to shallow subsurface flow in volcanic catchments of ages between 200000 and 82 million years. Thus, the change of major flow paths with time has already been studied at the timescale on the order of 100000 to millions of years, but little is known about how flow paths change during these first 10000 years of landscape development.

Areas with receding glaciers have been shown to be suitable for soil development studies (Crocker and Dickson, 1957; Douglass and Bockheim, 2006; He and Tang, 2008; Egli et al., 2010; Dümig et al., 2011; Vilmundardóttir et al., 2014; D'Amico et al., 2014). In the cool and humid climate regions of former glacial areas, the soils develop from mineral soils to soils with a highly organic topsoil. These organic soil types are less intensively studied with regard to their soil hydraulic behavior compared to mineral soils (Carey et al., 2007). It is known that these soils differ in their soil hydraulic properties from mineral soils (high total porosity - up to $90 \%$ - and a low bulk density; Carey et al., 2007), but little is known about how this development impacts water flow paths. Therefore, this study addresses the occurrence and the evolution of preferential flow during the first 10000 years of landscape evolution in glacial moraines in the Swiss Alps. More specifically, we test the hypotheses that (1) vertical subsurface flow path types and vertical extent of flow paths change through the millennia as (2) the proportion of macropore flow will increase due to the development of biopores, (3) the soil develops from a homogeneously mixed material into a depthdifferentiated soil system, and (4) physical weathering leads to a reduction in particle size and an increase in porosity.

Dye tracer experiments and an analysis of soil texture and soil physical properties were used to investigate how water flow paths evolve with hillslope age. The hydropedological approach (Lin, 2003) that links pedon (Quisenberry et al., 1993), landscape (Cammeraat and Kooijman, 2009), and hydrologic process studies has already been applied to the preferential flow phenomenon (Jarvis et al., 2012). Dye tracer experiments combined with digital image processing have been applied successfully to study preferential infiltration in soils (Weiler, 2001; Bogner et al., 2008; Blume et al., 2008; Laine-Kaulio et al., 2015; Hardie et al., 2011; Cheng et al., 2014). In our study we use this method to identify how flow paths change during the coevolution of soil, vegetation, and topography. Understanding the changes in preferential flow paths as a result of the natural coevolution of landscape-forming factors can provide valuable knowledge on how these systems can also change as a result of human intervention (Richter and Mobley, 2009). 


\section{Material and methods}

\subsection{Study site}

The study area is located in the foreland of the Stein glacier above the tree line in the central Swiss Alps, south of the Sustenpass in the Urner Alps (approximately $47^{\circ} 43^{\prime} \mathrm{N}$, $8^{\circ} 25^{\prime} \mathrm{E}$ ). Elevations range from 1900 to $2100 \mathrm{~m}$ a.s.l. The area lies in the polymetamorphic Erstfeld gneiss zone, which is part of the Aar massif (Blass et al., 2003). The geology is defined by metamorphosed pre-Mesozoic metagranitoids, amphibolites, and gneisses (Heikkinen and Fogelberg, 1980; Schimmelpfennig et al., 2014); thus the material is mainly acidic and rich in silicate. The closest official weather station is located $18 \mathrm{~km}$ away at Grimsel Hospiz $\left(46^{\circ} 34^{\prime} \mathrm{N}, 8^{\circ} 19^{\prime} \mathrm{E}\right)$ at an elevation of $1980 \mathrm{~m}$ a.s.l. For the norm period from 1981 to 2010 , the station recorded an annual mean temperature of $1.9^{\circ} \mathrm{C}$ and an annual precipitation of $1856 \mathrm{~mm}$. The precipitation distribution throughout the year is fairly uniform with a slight increase in the winter months (Schweizerische Eidgenossenschaft, 2016). The glacier foreland consists of moraines with unconsolidated glacial till. The humid and cool climate together with the nutrient-poor substrate and a relative high water permeability of the glacial till favor the formation of podsolic soils and humus in this area (Heikkinen and Fogelberg, 1980).

The moraines of the Stein glacier were exposed due to its retreat to the south. Four moraines were selected for this study (see Fig. 1). Schimmelpfennig et al. (2014) conducted a detailed dating study of the Stein glacier moraines, based on high-sensitivity beryllium-10 moraine dating and found that the ages of three moraines range between 160 to 10000 years. The age of a fourth moraine was dated to 30 years based on maps and aerial photos.

The oldest moraine with an age of 10000 years is facing northeast. The second oldest moraine with an age between 2000 and 3000 years is the only one facing south. The two youngest moraines were exposed in the years 1860 and 1980-1990 and thus have an age of 160 and 30 years, respectively. Both moraines are facing northeast and are located closer to the glacier tongue at a distance of approximately $1 \mathrm{~km}$ from the oldest moraines. Both moraines are south of the glacial lake Steinsee (1930 m a.s.1.), which is a proglacial lake that was formed by the glacier retreat in 1924 (Blass et al., 2003).

The vegetation of the moraines was mapped in summer 2017 (Maier et al., 2019). Pronounced differences in vegetation coverage and species distributions were found among the four age classes. The vegetation of the oldest moraine was dominated by a variety of prostrate shrubs together with small trees and several grasses. On the 3000-yearold moraine, a grassland cover with fern, mosses, sedges, and forbs was found. The two youngest moraines however showed a lower degree of vegetation complexity. On the 160year-old moraine, a combination of grasses, lichen, forbs, and shrubs was present. The youngest moraine still shows only a sparse vegetation cover with mainly grass, moss, forbs, and a few shrubs.

\subsection{Field experiments}

The dye tracer experiments were conducted between mid July and mid August 2018. We used Brilliant Blue FCF as dye tracer due to its good visibility, high mobility, and nontoxicity. We used a concentration of $4 \mathrm{~g} \mathrm{~L}^{-1}$, at which the tracer shows good sorption and visibility (Weiler and Flühler, 2004). Three study plots were selected at each moraine, based on the degree of vegetation complexity (low, medium, and high complexity). Vegetation complexity is characterized by vegetation coverage, the number of species, and the plant functional diversity. The functional diversity is calculated based on specific leaf area, nitrogen content, leaf dry matter content, Raunkiær's life form, seed mass, clonal growth organ, root type, and growth form. The collection of the required data and calculation of the vegetation complexity was done by the geobotany group of the University of Freiburg and is described in more detail in Maier et al. (2019).

The size of each study plot was $1.5 \mathrm{~m} \times 1.0 \mathrm{~m}$. The distances between the three study plots at each moraine ranged from 10 to $100 \mathrm{~m}$. Each plot was further divided into three equal subplots of $0.5 \mathrm{~m} \times 1.0 \mathrm{~m}$. Figure 2 shows the experimental design at each moraine and illustrates the irrigation procedure.

The subplots were irrigated with three different amounts of dyed water $(20,40$, and $60 \mathrm{~mm})$ and an irrigation intensity of $20 \mathrm{~mm} \mathrm{~h}^{-1}$. The irrigation intensity is relatively high with a return period of 2.8 years (Fukutome et al., 2017). In preparation of the tracer application, large vegetation in the form of shrubs and bushes was cut off to a height of a few centimeters to reduce interception. The tracer was applied with a hand-operated sprayer connected to a battery-powered pump which guaranteed a constant pressure for a uniform flow rate of $60 \mathrm{~L} \mathrm{~h}^{-1}$. For a time-efficient irrigation of the three subplots with three irrigation amounts, the irrigation procedure was divided into three steps. In the first step, all three subplots were irrigated simultaneously for $60 \mathrm{~min}$ in a sequence of 5 min of irrigation and a $5 \mathrm{~min}$ break. This provides an application of $20 \mathrm{~mm}$ to all three subplots. After finishing the first step the first subplot was covered to avoid any additional water input. In a second step, the other two subplots were simultaneously irrigated for an additional $60 \mathrm{~min}$ in a sequence of $5 \mathrm{~min}$ of irrigation and $10 \mathrm{~min}$ breaks. This provides an application of an additional $20 \mathrm{~mm}$ to each of the two remaining subplots. In the last step, only the third subplot was irrigated for $60 \mathrm{~min}$ in a sequence of $2 \mathrm{~min}$ of irrigation and 10 min breaks, while the other two plots remained covered providing an additional $20 \mathrm{~mm}$ to this subplot. After the end of tracer application, the entire plot was covered to avoid any disturbance by natural rainfall. 

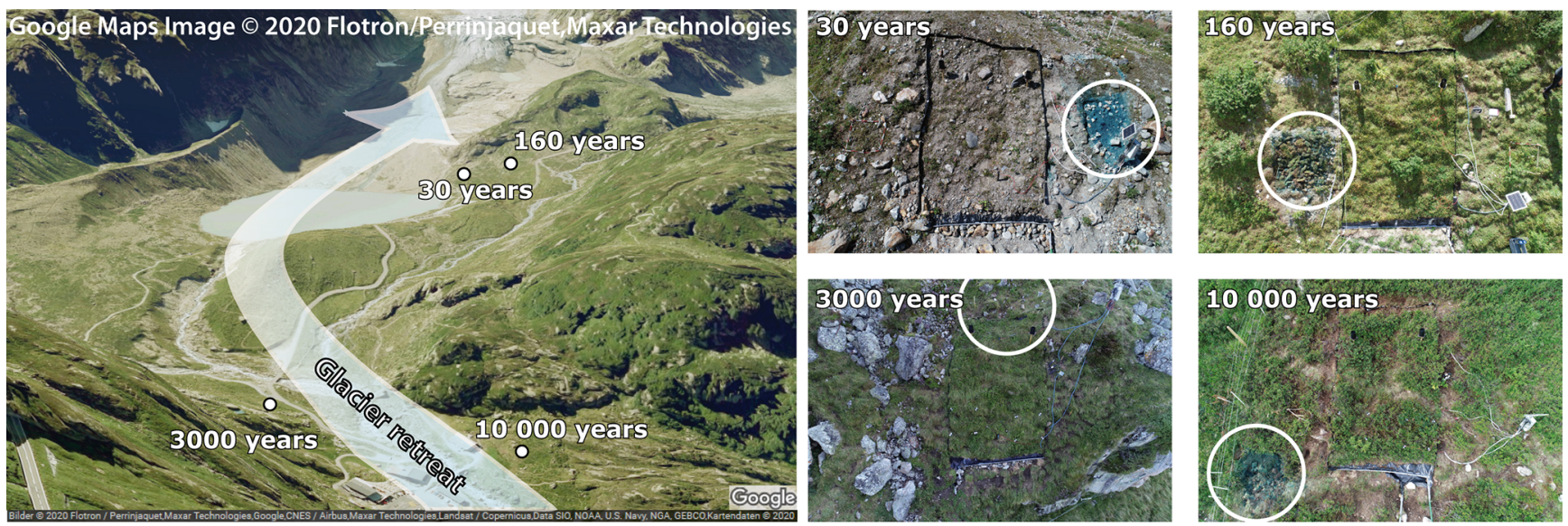

Figure 1. Location (left) and surface cover (right) of the four selected proglacial moraines of the Stein glacier. White circles show locations of one of the three Brilliant Blue experiment plots per age class. Photo of the location is provided by (C) Google (2020). Photos of the 30-, 160-, and 10000 -year-old moraines were taken after the Brilliant Blue experiment (photos taken by Florian Lustenberger).

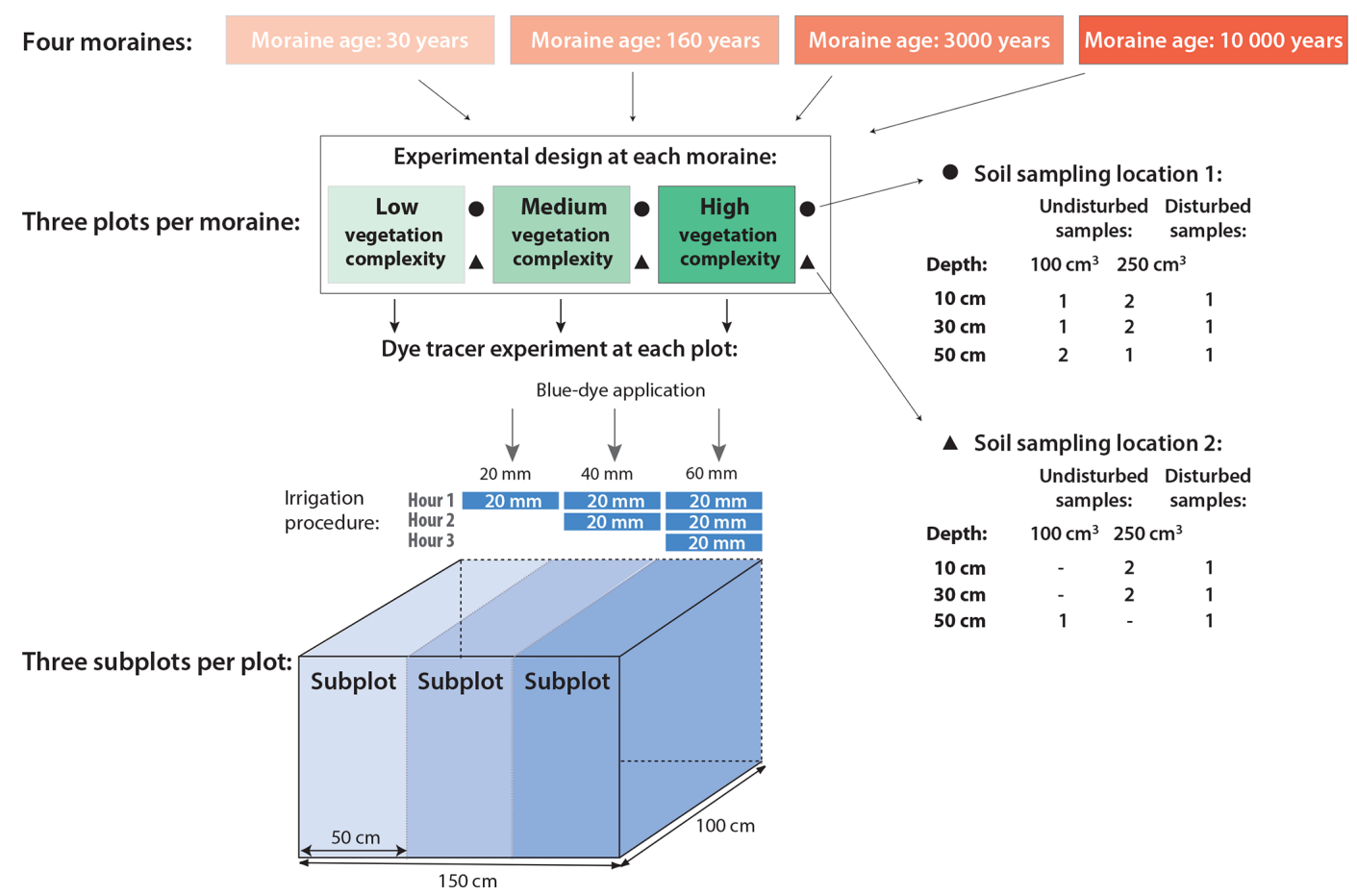

Figure 2. Illustration of the experimental design and soil sampling scheme at each moraine.

The next day each subplot was excavated in up to five profiles of 7 to $10 \mathrm{~cm}$. After the profile cuts were made with pickaxes, spades, and hand shovels, the profile walls were cleaned. Hanging roots were cut off, and rocks were not removed but made visible. The profiles of each subplot were photographed with a Panasonic Lumix DMC-FZ18 camera and at a resolution of 2248 pixels $\times 3264$ pixels. A big umbrella was used to provide a uniform light distribution in the photographs and to avoid direct sunlight. A wooden frame for geometric correction and a grayscale (Kodak) attached to the frame (Fig. 3) for later color adjustment were included in the photographs. Since dye tracer experiments only provide snapshots of flow patterns at $24 \mathrm{~h}$ after the irrigation, we cannot exclude the possibility that initial preferential flow paths were obliterated by a later downward movement of the infiltration front. However, as the probability of this special case is relatively low, we assume that these snapshots are a viable basis for the comparison of characteristic flow patterns along the moraine ages. 


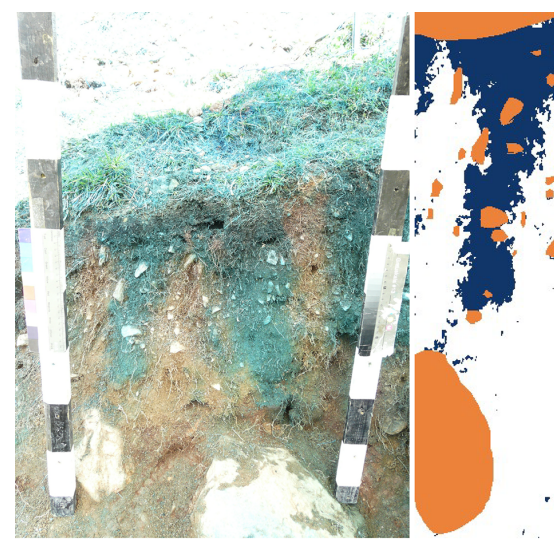

(a)

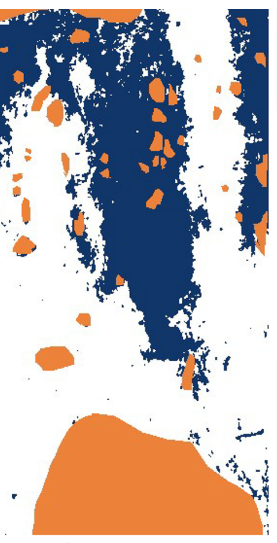

(b)

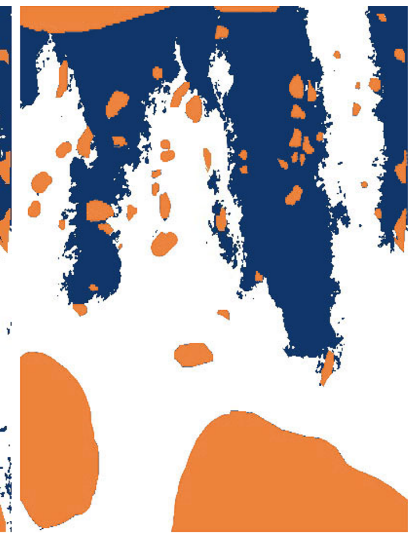

(c)

Figure 3. Exemplary image analysis procedure for the $40 \mathrm{~mm}$ irrigated subplot at the 3000 -year-old moraine. (a) Photograph of the vertical soil profile with a wooden frame and an attached grayscale. (b) Software-generated tricolor image of the photograph. (c) Manually corrected tricolor image. Blue indicates stained soil; white indicates unstained soil; and orange indicates rocks.

\subsection{Image analysis}

The image analysis procedure by Weiler (2001) was used to generate tricolor images of the photographs showing stained and unstained areas (Fig. 3). A detailed description of the method can be found in Weiler and Flühler (2004). Instead of using the original IDL (Interactive Data Language) software package, a similar Python version was used. Basically, geometric correction, background subtraction, and color adjustment were carried out to correct differences in image illumination and changes in the spectral composition of daylight. The delineation of rocks and plants was done manually. In the resulting tricolor image, the horizontal and vertical length of a pixel correspond to $1 \mathrm{~mm}$. Due to poor lighting conditions or a heterogeneous background color distribution in the soil caused by material transitions, small stones, or organic matter, the image analysis software was not able to recognize all large dye stains as coherent objects. Thus, a manual correction of the images using the photographs was necessary (see Fig. 3).

For a quantitative comparison of the dye patterns, the maximum infiltration depth, the volume density, and surface area density, as well as the stained path width, were calculated. These parameters are frequently used for an objective comparison and description of the dye patterns (Weiler and Flühler, 2004; Bachmair et al., 2009; Laine-Kaulio et al., 2015; Cheng et al., 2014; Gimbel et al., 2016; Laine-Kaulio et al., 2015; Mooney and Morris, 2008; Öhrström et al., 2002). Volume and surface area density are originally steorological parameters which are used to relate three-dimensional structures to measured two-dimensional parameters (Weibel, 1979). The volume density corresponds to the dye coverage and can be derived from one-dimensional information by calculating the fraction of stained pixels for each depth. The volume density profile is defined by the fraction of stained pix- els per depth and is calculated as the average of all excavated profiles per plot. The surface area density in one dimension is calculated by using the intercept density, which describes the number of intercepts between stained and unstained pixels divided by the horizontal width of the soil profile. The profile of the surface area density describes the amount of intercepts per depth and is then also averaged over all photographed profiles per plot. Volume density provides no information about whether the stained area is the sum of many small fragments or a few large ones; thus the volume density alone should not be used to characterize flow patterns, and the surface area density should be used as a supplementary parameter. A high surface area density indicates a large number of small features.

Following the method described by Weiler (2001), the resulting dye patterns were next classified into flow type categories based on the proportions of three selected stained path width classes (stained path width $<20,20-200 \mathrm{~mm}$, and $>200 \mathrm{~mm}$ ) relative to the volume density. The stained path width is equal to the horizontal extent of a stained flow path (Weiler, 2001). This classification method distinguishes between five flow types: (1) macropore flow with low interaction, (2) mixed macropore flow (low and high interaction), (3) macropore flow with high interaction, (4) heterogeneous matrix flow and finger flow, and (5) homogeneous matrix flow. Dye patterns which cannot be classified as one of these flow types are categorized as undefined. The classification method based on proportions of the classes of stained path width is illustrated in Fig. 4.

This method is based on the assumption that the dye patterns are mainly controlled by certain preferential flow processes and that each flow process creates a characteristic dye pattern that can be described by the extent and distribution of stained features. 


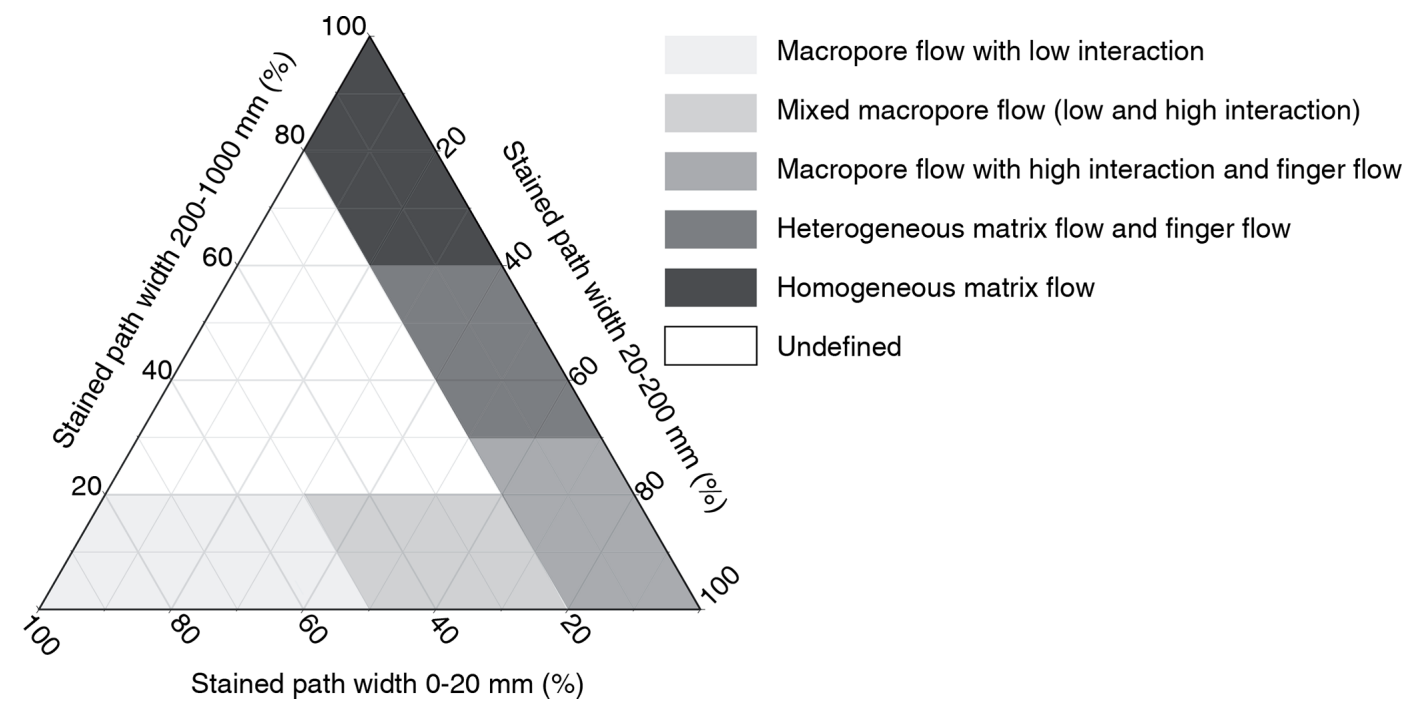

Figure 4. Ternary diagram for flow type classification based on the proportion of the three stained path width classes (after Weiler, 2001).

This method was proven to be suitable for the investigation of Weiler (2001) and Weiler and Flühler (2004) and was also used in a variety of additional studies (Bachmair et al., 2009; Gimbel et al., 2016; Mooney and Morris, 2008). However, an extension of the flow type categorization was needed for our study site with soils of different ages, texture, and additionally a high stone content. In the extended classification, we avoid a clear differentiation between macropore flow and finger flow. The original classification assigns finger flow only when both classes of the medium-sized stained path width $(20-200 \mathrm{~mm})$ and the biggest stained path width ( $>200 \mathrm{~mm}$ ) account for approximately half of the dye coverage. This implies that finger flow is only prevalent when the dye pattern is characterized by a majority of broader stained path widths, ignoring the fact that the size of the finger-like flow paths can vary over a broad range (Wang et al., 2018). Thus, we argue that while finger flow and macropore flow are caused by different properties and flow mechanisms, they can lead to similar dye patterns and distributions of stained path width classes. This is especially the case for macropore flow with high interaction, which creates broader stained paths that could also be assigned to finger flow. Therefore, both flow types were considered in the extended classification for this class. Furthermore, it was observed that the presence of rocks within the image analysis interrupts homogeneous blue stained areas and thus leads to smaller stained path widths. Using the original classification scheme on a soil profile with high stone content suggests a heterogeneous flow pattern, which can be classified as heterogeneous matrix flow, finger flow, or macropore flow depending on the abundance of rocks. Therefore, an additional class has been introduced, which is used when homogeneous matrix flow between rocks takes place. The classification rule for the additional flow type class is based on the proportion of blue- dye coverage of the available permeable matrix space (profile width minus the sum of stone widths per row). If at least $95 \%$ of the permeable space is stained by blue dye, the flow type is classified as matrix flow between rocks.

\subsection{Soil sampling and laboratory analysis}

Soil samples were taken during August and September of 2018 close to each dye tracer plot. For grain size analysis, two disturbed bulk soil samples per depth were taken at 10,30 , and $50 \mathrm{~cm}$ depth at each plot. The total of 72 samples was analyzed in the laboratory between November 2018 and January 2019 by using a combination of dry sieving (grain sizes $>0.063 \mathrm{~mm}$ ) and sedimentation analysis (grain sizes $<0.063 \mathrm{~mm}$ ) with the hydrometer method (Casagrande, 1934). Organic matter removal was only possible by floating off the lighter fractions prior to grain size analysis. Since three plots were selected per moraine for the Brilliant Blue experiments, six samples per depth and age class (a total of 18 samples for each moraine) were available for the grain size analysis. Grain sizes between 2 and $0.063 \mathrm{~mm}$ were classified as sand, between 0.063 and $0.002 \mathrm{~mm}$ as silt, and smaller than $0.002 \mathrm{~mm}$ as clay. Grain size fractions of particles $<2 \mathrm{~mm}$ were calculated as weight percentages of total weight of particles $<2 \mathrm{~mm}$, thus excluding gravel and stones to avoid single larger stones shifting or dominating the distribution. The gravel and stone fraction was calculated separately as a weight percentage of the entire soil sample.

For the analysis of the structural parameters, soil samples were taken with sample rings to provide undisturbed cores which preserve the natural soil structure. At each plot, two $250 \mathrm{~cm}^{3}$ and one $100 \mathrm{~cm}^{3}$ undisturbed soil samples were taken at a depth of 10 and $30 \mathrm{~cm}$. Three samples of $100 \mathrm{~cm}^{3}$ were taken at $50 \mathrm{~cm}$ depth. Thus, per age class, nine samples per depth were available for the determination of the 
structural parameters of porosity and bulk density. A detailed overview of the sampling scheme at each plot is given in Fig. 2.

The porosity was determined in the lab using the water saturation method. For this method, sample weights were recorded at saturation and after drying at $105^{\circ} \mathrm{C}$. For saturation, the samples were placed in a small basin. The water level in the basin was increased stepwise by $1 \mathrm{~cm} \mathrm{~d}^{-1}$. When the water level reached the top of the soil sample and the sample was fully saturated, the bottom of the sample was sealed, and the weight at saturation was measured. Bulk density was determined by relating the dry mass after drying at $105^{\circ} \mathrm{C}$ to the sample volume. The loss on ignition is a measure of the organic substance in the soil and describes the proportion of the organic substance that was oxidized during annealing for $24 \mathrm{~h}$ at $550^{\circ} \mathrm{C}$. The loss on ignition was determined by drying subsamples (4-6g) for at least $24 \mathrm{~h}$ at $105^{\circ} \mathrm{C}$ and then at $550^{\circ} \mathrm{C}$. The ignition loss is then calculated by relating the weight loss after drying at $550^{\circ} \mathrm{C}$ to the sample weight after drying at $105^{\circ} \mathrm{C}$.

\subsection{Statistical analysis}

The nonparametric Kruskal-Wallis test was used to test the significance of the differences in the soil texture among the four moraines of differing age classes. It can be applied when the assumption of a normal distribution cannot be made and is also valid for small sample sizes. We applied the test to each grain size fraction across the four age classes. Average values were based on 18 samples per age class. The grain size distribution at $10 \mathrm{~cm}$ depth of the oldest moraine was excluded from consideration, since due to the high organic content not all organic matter could be removed, and the results may therefore be erroneous.

\section{Results}

\subsection{Soil texture and structural parameters}

Comparing the depth-averaged soil texture over the millennia, we find that while the soil texture at the youngest moraine mainly consists of sand, the grain sizes decrease over the millennia with silt being the largest fraction after 10000 years (Fig. 5). Clay content increased with age for the three older moraines, with the youngest moraine being the exception (having the second-highest clay content). The Kruskal-Wallis test with a 0.05 confidence level showed that differences in grain size fractions among the four age classes were statistically significant ( $p$ values $<0.05$; sand of $p=0.0013$, silt of $p=0.0006$, and clay of $p=0.0018$ ).

A significant reduction in grain size over time was observed, which is most pronounced between 3000 and 10000 years of soil development. The gravel and stone fraction is roughly the same at the three younger moraines and significantly lower at the oldest moraine (Fig. 5b). The structural (a)

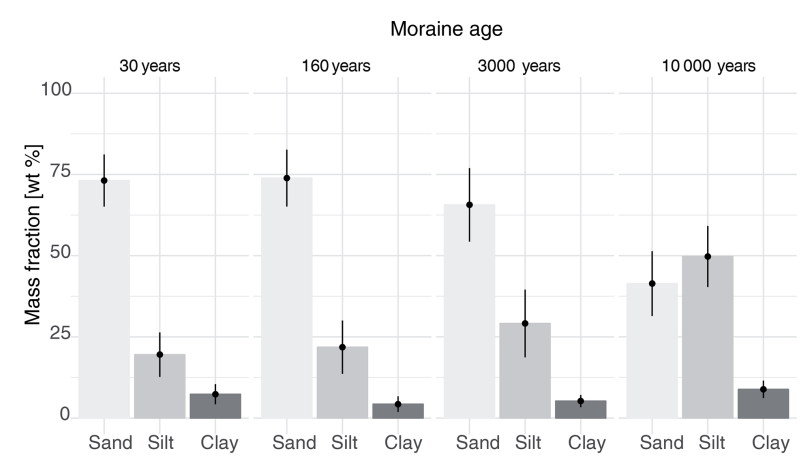

(b)

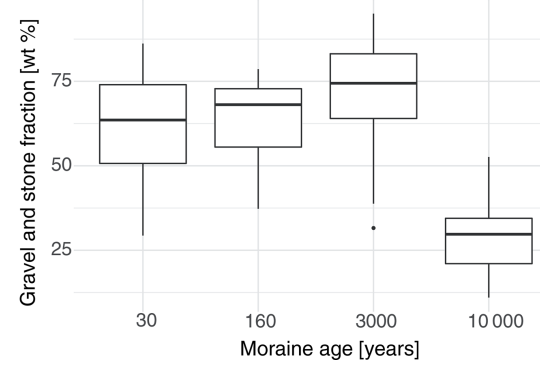

Figure 5. (a) Profile-averaged grain size fractions for the four moraines. Fractions are percentages of the fine earth fraction $(<$ $2 \mathrm{~mm}$ ). (b) Profile-averaged gravel content $(>2 \mathrm{~mm}$ ) calculated as the percentage of the entire sample weight. Each average is based on 18 samples.

parameters of porosity and bulk density also show a clear trend with age, with porosity increasing and bulk density decreasing (Fig. 6).

The porosity observed at the youngest moraine ranges between 0.22 and 0.37 , with no pronounced differences among the three soil depths. The 160-year-old moraine has a higher porosity in the upper $10 \mathrm{~cm}$ than the 30 -year-old moraine. After 3000 years the increase in porosity continues but is now also visible in 30 and $50 \mathrm{~cm}$, but with much higher values at $10 \mathrm{~cm}$ (Fig. 6a). After 10000 years the porosity at $10 \mathrm{~cm}$ ranges from 0.6 to up to more than 0.8 . The other two depths also experienced a further increase in porosity. The decrease in bulk density is also most pronounced in the top layer of the soil (Fig. 6b). While after 30 years the bulk density in the upper $10 \mathrm{~cm}$ ranges around $1.7 \mathrm{~g} \mathrm{~cm}^{-3}$, the bulk density after 10000 years is much smaller and ranges between 0.2 and $0.7 \mathrm{~g} \mathrm{~cm}^{-3}$. After 3000 years the trend is also visible at 30 and $50 \mathrm{~cm}$.

The loss on ignition, as a measure for the organic matter content, shows an increase throughout the first 10 millennia of soil development, which is most pronounced in the upper soil layer (see Fig. 6c). At the two youngest moraines, the organic matter content is still very low $(<2 \mathrm{wt} \%$; percentage by weight). At these two age classes, the organic matter content is homogeneously distributed over the profile, with a slight tendency to higher values in the topsoil at the 160year-old moraine. The 3000-year-old moraine shows a strong 
Table 1. Linear rates of change in porosity, bulk density, and grain size between adjacent age classes calculated based on median values. Mass fraction: $\mathrm{mf} \%$.

\begin{tabular}{|c|c|c|c|c|c|c|c|c|c|}
\hline & \multicolumn{3}{|c|}{ Porosity $\left(\mathrm{yr}^{-1}\right)$} & \multicolumn{3}{|c|}{ Bulk density $\left(\mathrm{g} \mathrm{cm}^{-3} \mathrm{yr}^{-1}\right)$} & \multicolumn{3}{|c|}{ Grain size $\left(\mathrm{mf} \% \mathrm{yr}^{-1}\right)$} \\
\hline & $10 \mathrm{~cm}$ & $30 \mathrm{~cm}$ & $50 \mathrm{~cm}$ & $10 \mathrm{~cm}$ & $30 \mathrm{~cm}$ & $50 \mathrm{~cm}$ & sand & silt & clay \\
\hline \multicolumn{10}{|l|}{ Period (years) } \\
\hline $30-160$ & $5.1 \times 10^{-4}$ & $3.2 \times 10^{-4}$ & $1.1 \times 10^{-4}$ & $-1.3 \times 10^{-3}$ & $-1.4 \times 10^{-3}$ & $-9.1 \times 10^{-4}$ & $2.5 \times 10^{-2}$ & $1.5 \times 10^{-2}$ & $-2.0 \times 10^{-2}$ \\
\hline $160-3000$ & $9 . s 5 \times 10^{-5}$ & $4.6 \times 10^{-5}$ & $4.4 \times 10^{-5}$ & $-2.9 \times 10^{-4}$ & $-9.7 \times 10^{-5}$ & $-1.4 \times 10^{-4}$ & $-3.2 \times 10^{-3}$ & $3.2 \times 10^{-3}$ & $3.1 \times 10^{-4}$ \\
\hline $3000-10000$ & $1.6 \times 10^{-5}$ & $3.3 \times 10^{-5}$ & $2.6 \times 10^{-5}$ & $-7.6 \times 10^{-5}$ & $-7.4 \times 10^{-5}$ & $-4.5 \times 10^{-5}$ & $-3.3 \times 10^{-3}$ & $2.4 \times 10^{-3}$ & $3.2 \times 10^{-4}$ \\
\hline
\end{tabular}

(a)

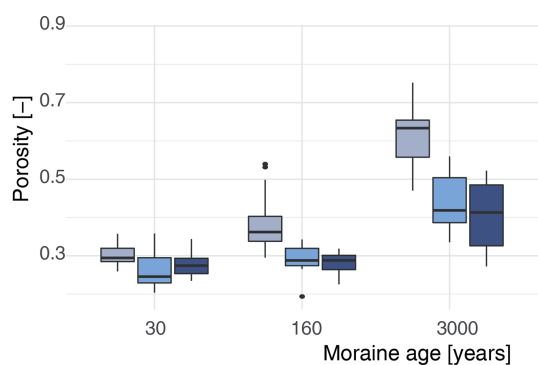

(b)

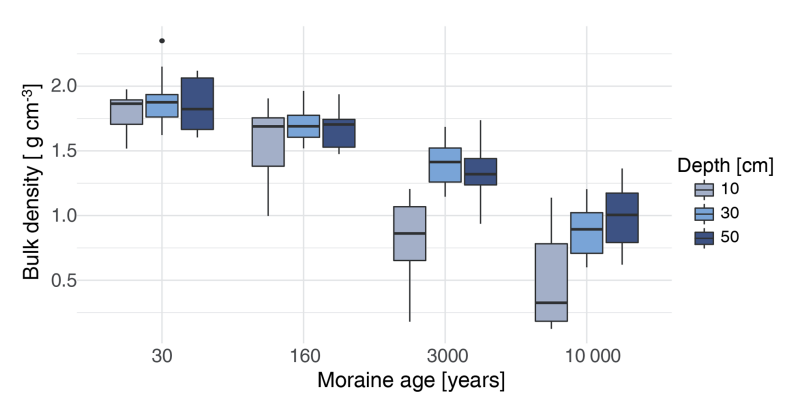

(c)

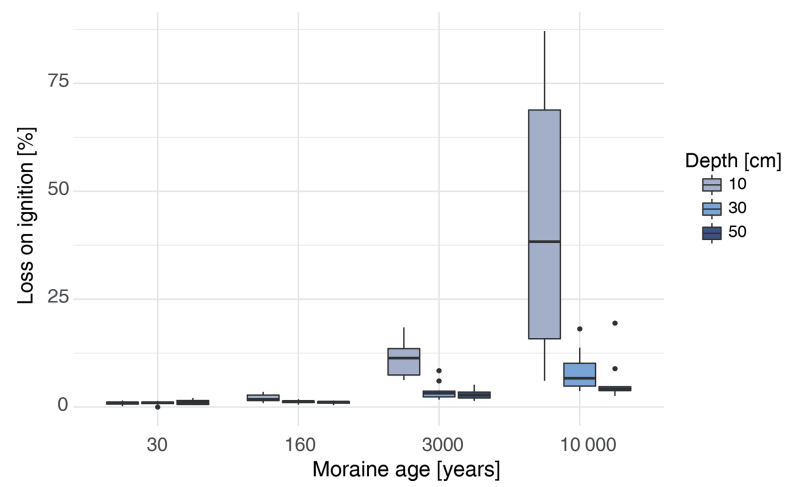

Figure 6. Evolution of soil porosity (a), bulk density (b), and loss on ignition (c) in 10, 30, and $50 \mathrm{~cm}$ depth.

increase in the organic matter content in the surface layer. At the oldest moraine, the trend of increasing organic matter continues in all three depths. Here, the organic matter content in the topsoil makes up to two thirds of the soil material. However, the organic matter content varies distinctly with a minimum of $6 \mathrm{wt} \%$ and a maximum of $87 \mathrm{wt} \%$. In deeper depths, the organic content also increases compared to the 3000 -year-old soil but remains below $20 \mathrm{wt} \%$.
Even though the differences in soil physical characteristics between 30 and 160 years are comparatively small, the rates of change during this initial phase are highest (Table 1). Between 160 and 3000 years, the rates of change are significantly reduced and remain in a similar range between 3000 and 10000 years.

\subsection{Vertical-dye pattern analysis}

Flow patterns traced with Brilliant Blue dye changed considerably with moraine age (Fig. 7). The volume density profile is a measure of the amount of blue dye per depth. The profile patterns of volume and surface area density show distinct differences among age groups, while differences between the vegetation complexity levels are not as clear (Figs. 7 and 8).

The volume density of the blue dye was classified in three selected groups of stained path width (Weiler, 2001). Additionally, the volume density of rocks was also classified in three groups (Fig. 7).

An analysis of the average or maximum infiltration depth based on the dye profiles was not possible because not all profiles could be excavated up to the maximum infiltration depth. In most cases, large boulders prevented further excavation or the infiltration depth was more than $1 \mathrm{~m}$. The latter was mostly the case at the youngest moraines. Only at the oldest moraine could a maximum infiltration depth be determined based on the dye profiles.

Combining the volume density profiles with the surface area density profiles, it is possible to derive whether the stained area described by the volume density is made up of many small flow paths or few large ones. The shapes of the volume density profiles and the surface area density of the youngest moraine are all very similar across the vegetation complexity levels and irrigation amounts. The youngest moraine has a higher volume density of flow paths in the top half of the soil profile than all other moraines (Fig. 7). There are almost no unstained areas. Beginning from approximately $30 \mathrm{~cm}$ depth, the volume density declines. The surface area density profiles show an opposite pattern (Fig. 8). The surface area density is smaller in the upper half and increases in the lower half of the profile. The combination of both parameters indicate a homogeneous staining in the top half, where interruptions of stained areas are only caused by rocks. In the lower part of the soil profiles the flow paths 


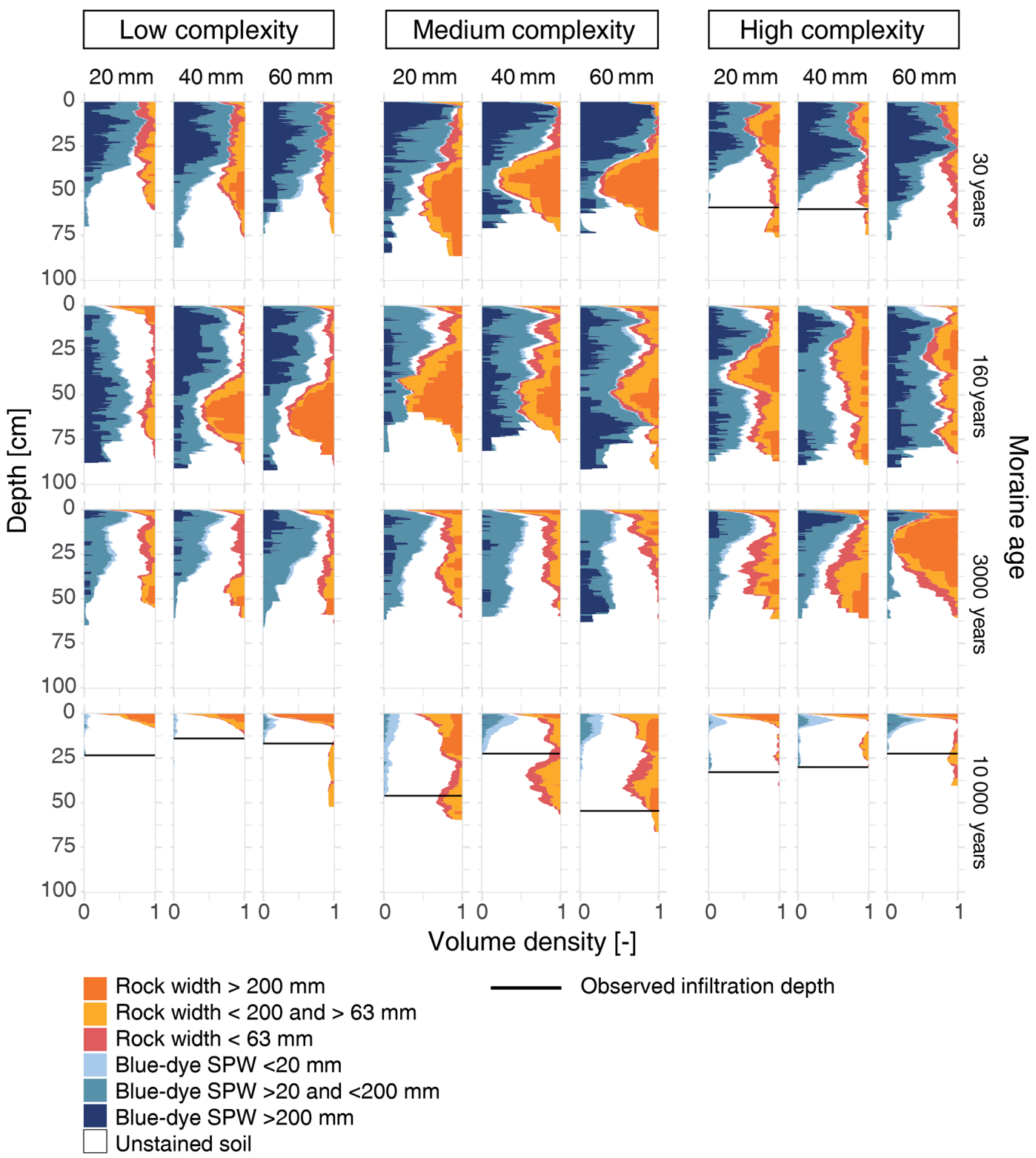

Figure 7. Volume density profiles per age class, vegetation complexity, and irrigation amount. The volume density is the fraction of stained pixels, here colored by flow path width (stained path width; SPW) and rock sizes.

are subdivided, which is indicated by the increase in surface area density (apparent at the plots at $30 \mathrm{~cm}$ depth for low, $25 \mathrm{~cm}$ depth for medium, and $50 \mathrm{~cm}$ depth for high vegetation complexity). This combined with a decline in volume density indicates a narrowing of the flow paths. For the plots of low and high vegetation complexity, the change in flow paths coincides with a layer of higher clay and silt content. This layer does not exist at the plot of medium vegetation complexity. In this case, the narrowing and splitting up of flow paths is caused by large rocks. No clear differences are visible between the different irrigation amounts. The proportion of classes of the stained path width is controlled by the existence of rocks. The maximum infiltration depth is either controlled by the position of the clay layer or is deeper than the profile depth and therefore cannot be determined.

Comparing the 160-year-old moraine to the youngest moraine, we find that the volume density is lower and the surface density is higher in the upper part of the profile. Also unstained areas (colored white in Fig. 7) are visible, which indicates that the higher surface density is not caused by the existence of rocks that split up a homogeneously stained area as was the case for the youngest moraine. In this case there is no total dye coverage of the permeable soil, and the preferential flow paths are initialized already near or at the soil surface. The surface density profiles show a decrease in the lower half of the soil profile, which either goes along with 

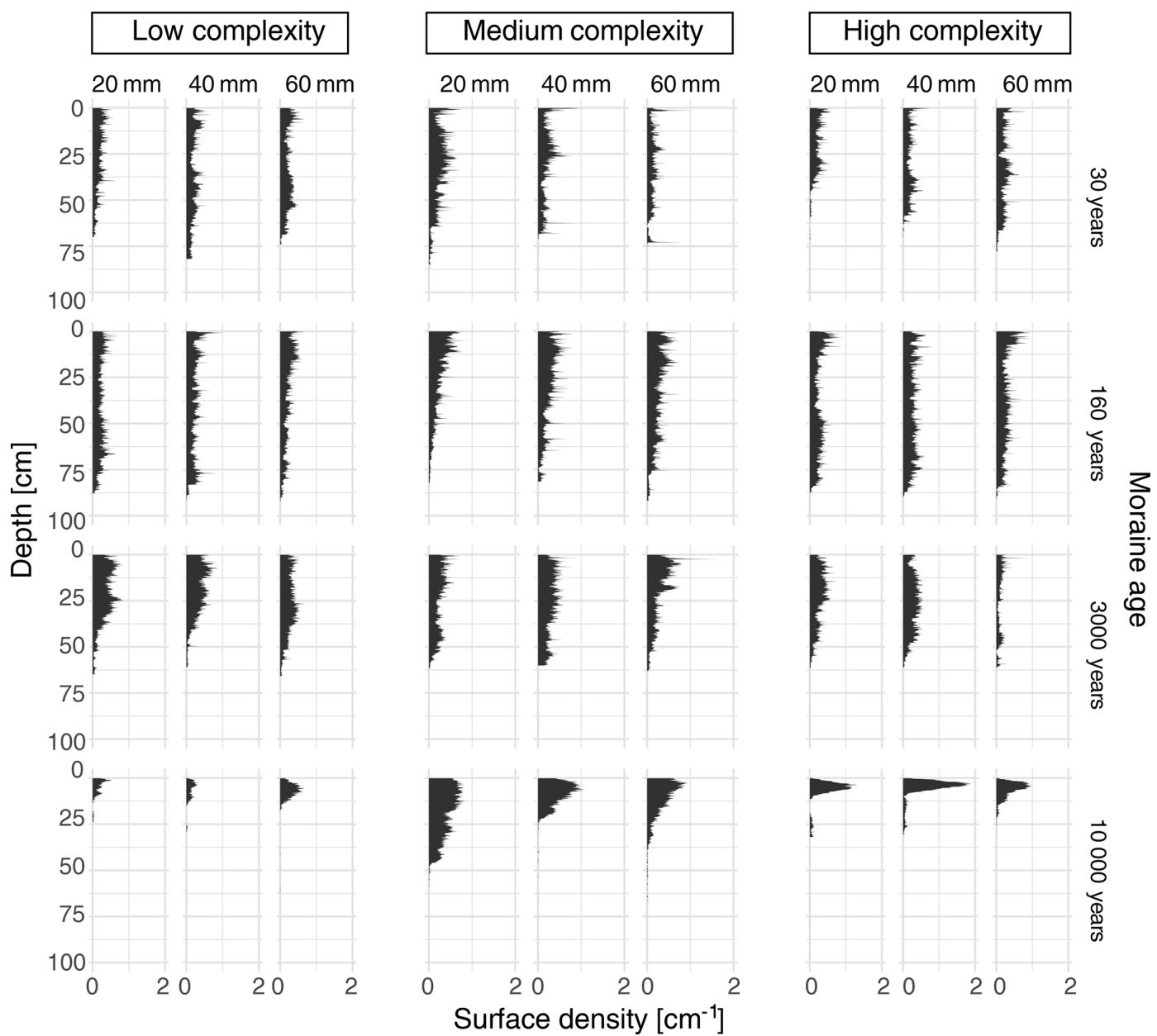

Figure 8. Surface area density profiles per age class, vegetation complexity, and irrigation amount (20, 40, and $60 \mathrm{~mm})$. A high surface area density indicates a large number of small features.

a decrease in the blue-dye coverage and an increase in the stone coverage or an increase in the blue-dye coverage without a significant change in stone coverage. Both indicate a reduction in the amount of separate flow paths and an increase in flow path widths, even if the permeable space is reduced due to an increase in rock content. Also the fraction of stained path width (SPW) bigger than $200 \mathrm{~mm}$ increases, which indicates that the dye plumes widen in deeper soil depths.

Compared to the two youngest moraines, the moraine of 3000 years shows in general a higher surface area density and a lower dye coverage combined with a higher fraction of an unstained permeable soil matrix. This indicates that similar to the 160-year-old moraine, water is transported in individual flow paths, but here there are more flow paths, and they have a smaller width. This can also be seen in the less frequent appearance of stained path width higher than $200 \mathrm{~mm}$ (Fig. 7). Similar to the 160-year-old moraine, preferential flow paths are already initialized at the top of the soil during infiltration (apparent from the white-colored areas across the profile in Fig. 7).
The oldest moraine with an age of 10000 years shows the highest surface area density and the lowest volume density combined with the lowest infiltration depths. The surface and volume density profiles show the same pattern: after a peak close to the soil surface, both density profiles show a decrease with soil depth. This means that the dyed water is only transported deeper into the soil via a few individual flow paths.

\subsection{Flow type classification}

Using the information in the volume density profiles and the stained path widths to characterize flow types (Weiler, 2001), we found a trend from a rather homogeneous flow pattern with matrix flow in a fast-draining coarse-textured soil at the youngest moraine to a more heterogeneous flow pattern with a mix of heterogeneous matrix flow and finger flow at both medium-age moraines (Fig. 9). While the flow characteristics of both the 160- and 3000-year-old moraine are dominated by finger flow with smaller stained path widths, this is much more pronounced in the 3000-year-old moraine. By 


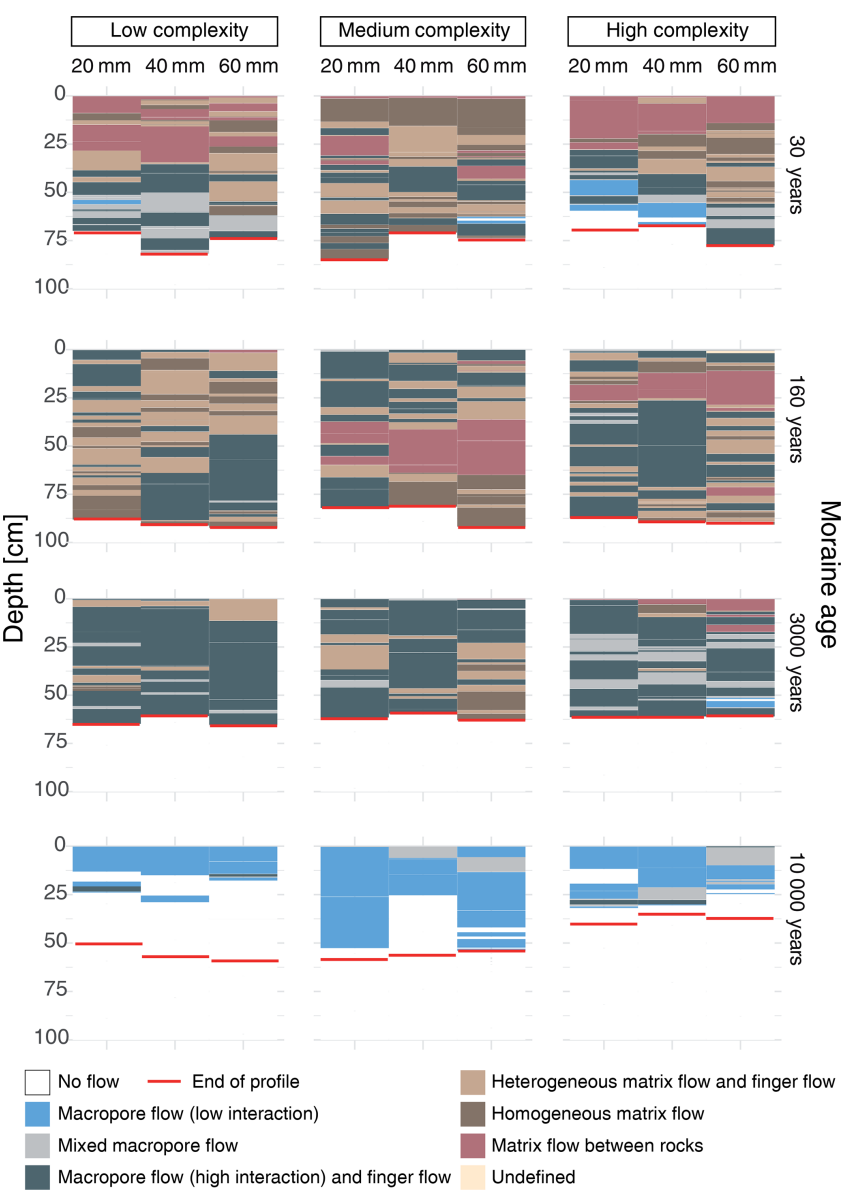

Figure 9. Profiles of flow types per age class, vegetation complexity, and irrigation amount.

contrast, the oldest moraine stands out clearly from the other age groups. Here, only the macropore flow is predominant. For the deeper soil layers, this was confirmed during the field experiments, since the few macropore flow paths were clearly visible. For the topsoil, the result is less certain, as the blue areas were very difficult to identify during the image analysis due to the very dark color of the organic layer.

The relative frequency distribution of the flow types per moraine age class derived from the results in Fig. 9 shows a clear shift in the flow type distribution along the age classes (Fig. 10). At the youngest moraine, all types of finger flow and matrix flow are present, and the frequency distribution does not show a distinct peak at any flow type. With increasing age, macropore flow becomes more and more important, and the peaks in the frequency distribution become more and more pronounced (Fig. 10).

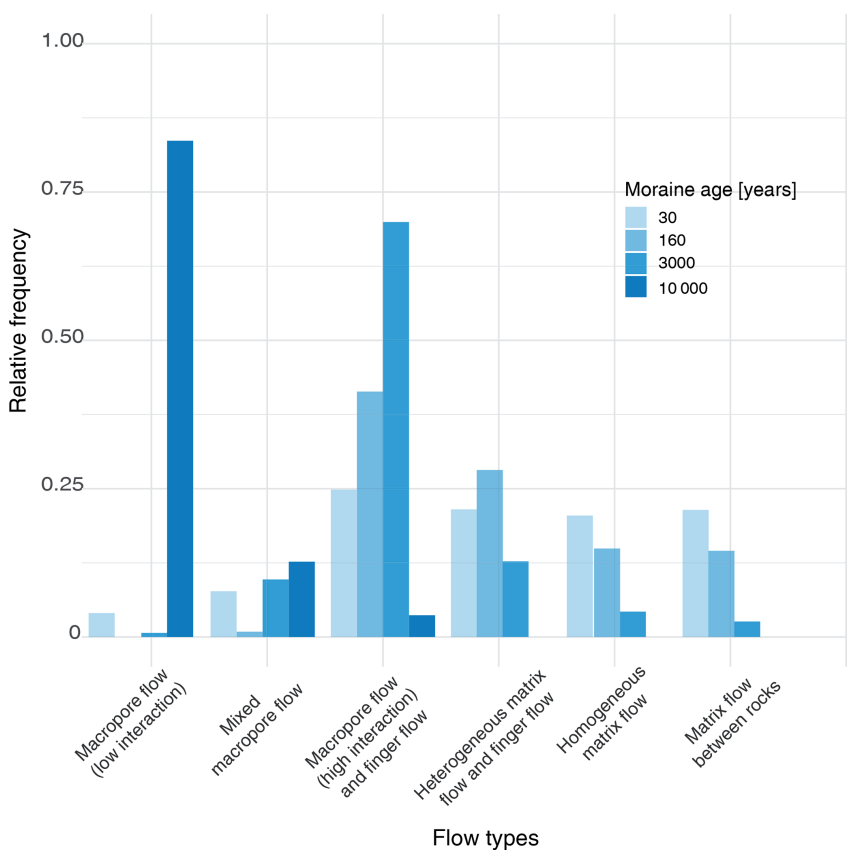

Figure 10. Relative frequency distribution of flow types of the four moraine age classes. Basically all observations fit into the six flow type categories. The fraction of observations categorized as "undefined flow type" is negligible.

\section{Discussion}

\subsection{Evolution of soil texture and structure}

The observation of bulk density, porosity, and soil texture show significant differences between the age groups as well as some clear trends with age. A detailed description of this data set can be found in (Hartmann et al., 2020).

\subsubsection{The early years: $30-160$}

The 30-year-old soil is characterized by coarse material, with a soil texture composed of almost three quarters of sand. The soil texture observed at the 160-year-old moraine does not differ strongly from the 30-year-old moraine, whereas slight changes are already evident in porosity and bulk density. These findings are similar to findings by Dümig et al. (2011), who found no specific trend in grain size distribution for soils in the range of 15 to 140 years at a soil chronosequence in the foreland of the retreating Damma glacier (Switzerland). They furthermore found a high variability in grain size distribution within the single age classes. However, in the same study a slight decrease in variability with increasing age and a noticeable higher clay content were found at the reference site with an age of more than 700 years. He and Tang (2008) also revealed a nonlinear increase in the maximum clay content for soils up to 180 years at a glacier foreland in a monsoon temperate region in southwestern China. 
After 160 years of soil development, the porosity in the top layer increased, and bulk density decreased. In general, these changes could be linked to changes in grain sizes, as the breakdown of particles leads to an increase in total pore space (porosity) and thus to a reduction in bulk density (Arvidsson, 1998). However, since changes in grain sizes were only marginal, the vegetation development, which includes an increase in the root activities, litter accumulation, and biological activities in the root zone, is likely the main cause for changes in bulk density and porosity (Neris et al., 2012; Carey et al., 2007). The vegetation coverage of both moraines differs significantly (Maier et al., 2019). The youngest moraine still shows only low vegetation cover with only single plants (mainly grasses and forbs) and little root mass with an observed maximum rooting depth of $15 \mathrm{~cm}$ (occasionally up to $30 \mathrm{~cm}$ ), whereas the 160 -year-old moraine already has a relatively closed vegetation cover with a combination of shrubs and smaller plants like forbs and grasses forming a loose root network with roots up to a maximum diameter of 5-6 mm and a maximum depth of $35 \mathrm{~cm}$ (as observed during the excavation of the soil profiles).

Similar findings in bulk density evolution were also observed by Crocker and Major (1955), who found a decrease in the bulk density over the first 200 years of soil development from more than $1.4 \mathrm{~g} \mathrm{~cm}^{-3}$ to less than $0.8 \mathrm{~g} \mathrm{~cm}^{-3}$ for glacial till in southeastern Alaska. A less pronounced reduction was also found by Crocker and Dickson (1957). He and Tang (2008) found a reduction for the time span of 180 years from approximately 1.42 to $0.95 \mathrm{~g} \mathrm{~cm}^{-3}$ that was also more distinct in the upper horizon. Vilmundardóttir et al. (2014) revealed at a glacier foreland in southeastern Iceland under maritime climate conditions a reduction from 1.36 to $1.07 \mathrm{~g} \mathrm{~cm}^{-3}$ for a time span of 120 years. All studies mentioned above linked this decrease in bulk density to the vegetation development with time.

\subsubsection{Intermediate stage: 3000 years}

At 3000 years of soil development we observe a distinct increase in silt and a reduction in sand content, and this development continues, as observed in the 10000-year moraine, where the silt content now makes up the largest share. These findings agree with findings by Douglass and Bockheim (2006), who studied several moraines in Buenos Aires with ages ranging from 16000 years to 1000000 years and found an accumulation of clay-sized particles with increasing age, but with a decrease in the accumulation rate over the years. A high fraction of silt is very common for soils in mountain areas (Ellis, 1992). Physical weathering due to high fluctuations between day and night temperature and freezing cycles (Birse, 1980) leads to a reduction in grain size, without changing the particle mineralogy (Ellis, 1992).

The soil material at the 30 -year-old moraine showed a relatively uniform porosity and bulk density throughout the profile. After 3000 years, porosity increases, and bulk density decreased even further, and this development is now also visible in deeper soil depths. The continuous increase in porosity and reduction in bulk density can be attributed to the continuing change in soil texture on the one hand and on the other hand to the pronounced vegetation development. Especially the latter, with the resulting accumulation of soil organic matter (see Fig. 6c) and the growth of an even denser root network that is now over $35 \mathrm{~cm}$ deep, is the main cause for the pronounced changes in the topsoil.

\subsubsection{The late stage: 10000 years}

The oldest moraine shows a significantly higher silt content and porosity compared to the 3000 -year-old moraine and a significantly lower bulk density. The change is visible at all soil depths, with the porosity in the uppermost depth being distinctly higher than the other depths. These differences in soil properties between the soil layers also indicate a progressive formation of distinct horizons in the soil.

The significantly higher porosity in the upper layer of the oldest moraine is caused by its thick organic layer (thickness up to $20 \mathrm{~cm}$ ), which is characterized by porosity of up to $90 \%$ (this was also found by Nyberg, 1995, in sandy-silty till on the western coast of Sweden and Carey et al., 2007, in organic soils in a permafrost region in northwestern Canada).

Musso et al. (2019) investigated the evolution of pore sizes in the top $5 \mathrm{~cm}$ at the same soil chronosequence and found an increase in the number of small soil pores and a decrease in the relative proportion of macropores (pore diameter $>0.05 \mathrm{~mm}$ ) between 160 and 10000 years. Thus the high porosity in the organic top layer at the oldest moraine is mainly composed of small pores. The top layer therefore has an increased water storage and water holding capacity. Due to the finer soil texture and higher porosity, the total water storage capacity of the oldest moraine is larger than that of the younger moraines.

An investigation of the saturated hydraulic conductivity evolution of the near surface (in 0-5, 5-20, and 20-40 cm) at the same chronosequence by Maier et al. (2019) found a decrease with increasing moraine age and soil depth. Saturated conductivity was found to be negatively correlated with the fraction of fine particles. The decrease in gravel content and the increase in silt seem to have an even a stronger effect on the saturated conductivity than the root network development (Maier et al., 2019).

\subsubsection{Soil heterogeneity and vegetation complexity}

It is well known that soil properties are spatially heterogeneous (Bevington et al., 2016; Hu et al., 2008). As it was not possible to account for this variability with a large sample size, i.e., with a large number of experiments, we decided to take a different approach. Assuming that vegetation cover and subsurface flow paths are strongly linked, we took the variability in vegetation cover as a proxy and used it in an at- 
tempt to bracket this variability: per moraine three locations that differ in their vegetation complexity (low, medium, and high) were chosen for soil sampling and the dye tracer experiments. The analysis of the structural soil properties shows that there is a slight increase in spatial heterogeneity with age, especially in the topsoil (increase in the interquartile ranges for all properties in the top layer in Fig. 6), but occasionally also individual depths show a higher heterogeneity, irrespective of age.

The flow path analysis differentiated according to the vegetation complexity showed no systematic influence of the complexity level on the results. Heterogeneities within the individual experimental subplots were taken into account by averaging the volume density and surface area density across the five vertical profiles per subplot instead of relying on individual profiles. We therefore assume that the results of the flow path analysis are sufficiently representative to investigate their evolution across the chronosequence.

\subsection{Evolution of flow paths}

The flow type classification by Weiler (2001) was used to classify the volume density patterns into flow type categories. A comparison between the observations made during the excavation and the derived flow types showed that in this case an adaptation of the flow type classification was necessary. On the one hand, this adaptation involved the treatment of rocks to prevent misclassification, and, on the other hand, we introduced the possibility of finger-like flow paths with smaller widths. After these adaptations the derived flow types correspond well with the observations made in the field.

The observed staining patterns and derived flow types show a significant difference between the age groups, whereas no significant difference was observed with respect to vegetation complexity and irrigation amount.

\subsubsection{The early years: $30-160$}

At the 30-year-old moraine, the water infiltrates homogeneously into the soil, probably due to the very low vegetation coverage and the coarse material texture. The dye pattern showed a mainly homogeneous staining of the soil material; thus derived flow types are mainly matrix flow in the form of homogeneous and heterogeneous matrix flow as well as matrix flow between rocks. Also finger flow occurs at the boundary to the clay layer or is caused by large blocks of rock, which are surrounded by clay. The determined macropore flow takes place only within the clay layer at a depth below $50 \mathrm{~cm}$. In the clay layer, no significant biopores were identifiable, which is why it is assumed that the water is transported in cracks or along material interfaces. The upper coarse soil material with large pores and a low water holding capacity causes the water to be transported quickly deeper into the soil.
After 160 years, the derived predominant flow types shift to heterogeneous matrix flow and finger flow. The observed widening of the dye plumes in deeper soil depths might be caused by a change in material or a reduction of hydrophobicity with soil depth where the influence of plants and organic material decreases (Blume et al., 2009). The dye coverage images show unstained soil areas starting also at the top of the soil profile, which indicates that preferential flow paths are initialized already at the soil surface or in the nearsurface layer. This was also observed during the irrigation, where we saw that the irrigated water often mainly infiltrated in depressions. Grass patches also tend to inhibit infiltration. It was observed that in the presence of dense grass patches, the water infiltrated only next to the patches, leaving the area below the patches unstained.

\subsubsection{Intermediate stage: 3000 years}

Similar observations were made at the 3000-year-old moraine. The image analysis revealed that preferential flow paths start at the soil surface and thus are initiated by vegetation and microtopography causing a heterogeneous infiltration pattern. Field observations also revealed that heterogeneous infiltration was not only created due to dense grass patches but also occurred under relatively homogeneous grass cover. A laboratory test of the water drop penetration time (DeBano, 1981; Doerr et al., 2000) on a soil sample of the upper soil material showed that the organic layer is highly water repellent in dry conditions (air dried for 2 weeks; water drop penetration time $>10 \mathrm{~min}$ ). An increase in the hydrophobicity index (Tillman et al., 1989) with increasing moraine age was also found by Maier et al. (2019). Thus, we conclude that the hydrophobicity of the organic top layer has a big impact on infiltration and the initiation of unstable flow. Unstable flow occurs when horizontal wetting fronts break into fingers or preferential flow paths during the downward movement (Hendrickx and Flury, 2001). Compared to the 160-year-old moraine, the 3000-year-old moraine is characterized by a higher number of narrower preferential flow paths.

The derived dominant flow type class at the 3000-year-old moraine is macropore flow with high interaction and finger flow. Of both possible flow types, finger flow is the prevalent flow process causing the dye pattern. Several studies linked the formation of finger-like flow paths to hydrophobic properties of the soil (Wallach and Jortzick, 2008; Dekker and Ritsema, 2000; Ritsema and Dekker, 1994; Blume et al., 2008; Wang et al., 2018; Hardie et al., 2011). It is assumed that hydrophobic compounds that are released during the decay of litter (Reeder and Jurgensen, 1979) or by root activity (Doerr et al., 1998) coat soil particles or are deposited in the pore space and thus create a hydrophobic soil matrix (Doerr et al., 2000). The humid and cool climate of former glacial areas leads to a slow decomposition of vegetation and thus 
to an accumulation of hydrophobic compounds (Doerr et al., 2000).

\subsubsection{The late stage: 10000 years}

At the oldest moraine, we saw a distinctly shallower infiltration depth (Fig. 7). During the experiment, no surface runoff was observed. Most of the water was stored in the organic top layer. The soil beneath the top layer was almost completely unstained, and water was transported only via a few macropores into deeper layers. A dense network of roots was only observed in the organic top layer, which included the thicker roots of the alpenrose (Rhododendron ferrugineum). The root network in the soil underneath was less dense with roots of smaller diameters but extended to a depth of more than $50 \mathrm{~cm}$. Although the vegetation cover has been reduced to decrease interception, the interception storage capacity at the oldest moraine is still comparatively high. Thus, a reduction in the water available for infiltration cannot be ruled out.

\subsubsection{Impact of rocks}

The rock content at the 30-, 160-, and 3000-year-old moraines is relatively high, with especially large rocks (widths $>20 \mathrm{~mm}$ ) in deeper parts of the soil (Figs. 5b and 7). The large rocks lead to a reduction of the permeable area and thus can cause funnel flow (Hendrickx and Flury, 2001). This type of preferential flow was especially observed at the youngest moraine, where large boulders $(>25 \mathrm{~cm})$ located at deeper soil depths were surrounded by unstained fine-textured material. Smaller-sized rocks in the upper part seemed not to have an influence on water transport (apart from reducing the flow-through volume), since these rocks and the surrounding soil were completely stained.

A splitting of flow paths caused by rocks was also observed a few times at the 160- and 3000-year-old moraines. In this case, water flowing past the sides of medium-to-largesized rocks creates a type of finger flow that is not caused by water repellency or air entrapment. The tendency of higher rock contents to increase the number of flow paths was also found by Bogner et al. (2014).

\subsubsection{Flow path controls along the age gradient}

Integrating all of our findings on soil structural parameters, texture, vegetation cover, and flow path patterns provides an overview over their coevolution and highlights the derived major flow path controls (Fig. 11).

Along the coevolution of soil and vegetation over 10000 years the major controls of subsurface flow paths change. At the youngest moraine flow paths are only controlled by soil texture. The coarse material leads to the deep downward movement of the infiltration front. Preferential flow paths only occur at the interfaces between coarse and finer material.
At the medium-age moraines, flow paths are mainly controlled by vegetation shielding, microtopography, and hydrophobicity. The latter is assumed to have an increased impact at the 3000-year-old moraine. After 10000 years of hillslope evolution, subsurface water transport is highly preferential and controlled by flow paths caused by root channels or boundaries of textural classes. Water storage in the organic layer which is also the main rooting horizon increases strongly.

\section{Conclusions}

Using Brilliant Blue dye experiments and soil sampling, we investigated the evolution of water transport paths along soilforming processes. To our knowledge, this is the first study examining flow path evolution across the millennia in such detail. The evolution of the grain size distribution shows that grain size decreases with increasing age. The biggest changes are in the sand and silt fraction. Furthermore, water flowdefining structural parameters such as porosity and bulk density change during soil development, resulting in an increasing water storage capacity with age. The depth-dependent evolution of these parameters supports our hypothesis that the soil material develops with increasing age from a homogeneously mixed material to a depth-differentiated soil system with vertical gradients in flow and storage defining soil properties. Changes in these flow-defining parameters are caused by the evolution of grain size distribution and vegetation.

The derived flow types also support our hypothesis that vertical subsurface flow path types and their vertical extent change through the millennia. Flow types change from a homogeneous matrix flow in a fast-draining coarse-textured soil to a heterogeneous matrix and finger flow over the first 1003000 years. At very young moraines, the water is homogeneously distributed within the soil matrix. However, the water storage capacity is relatively low due to the coarse material, and water is transported quickly deeper into the soil due to the high drainability. At the medium-age moraines, water is transported preferentially via finger-like flow paths deeper into the soil by leaving parts of the soil dry. With increasing hillslope age, we expected macropores induced by root activities to become more important. After 10000 years, where the amount of soil matrix macropores decreased significantly, the macropore flow along roots plays an important role but is not very pronounced. Only a few roots reach beyond the organic top layer. However, this allows for a fast transport of water from the upper layer into deeper soil. The organic top layer has a pronounced influence on the soil water budget, by storing a significant amount of water. The increase in water storage with increasing age of the moraines also caused a reduction in infiltration depth.

The proportion of preferential flow paths increases with soil age. Preferential flow is, however, not only caused by 


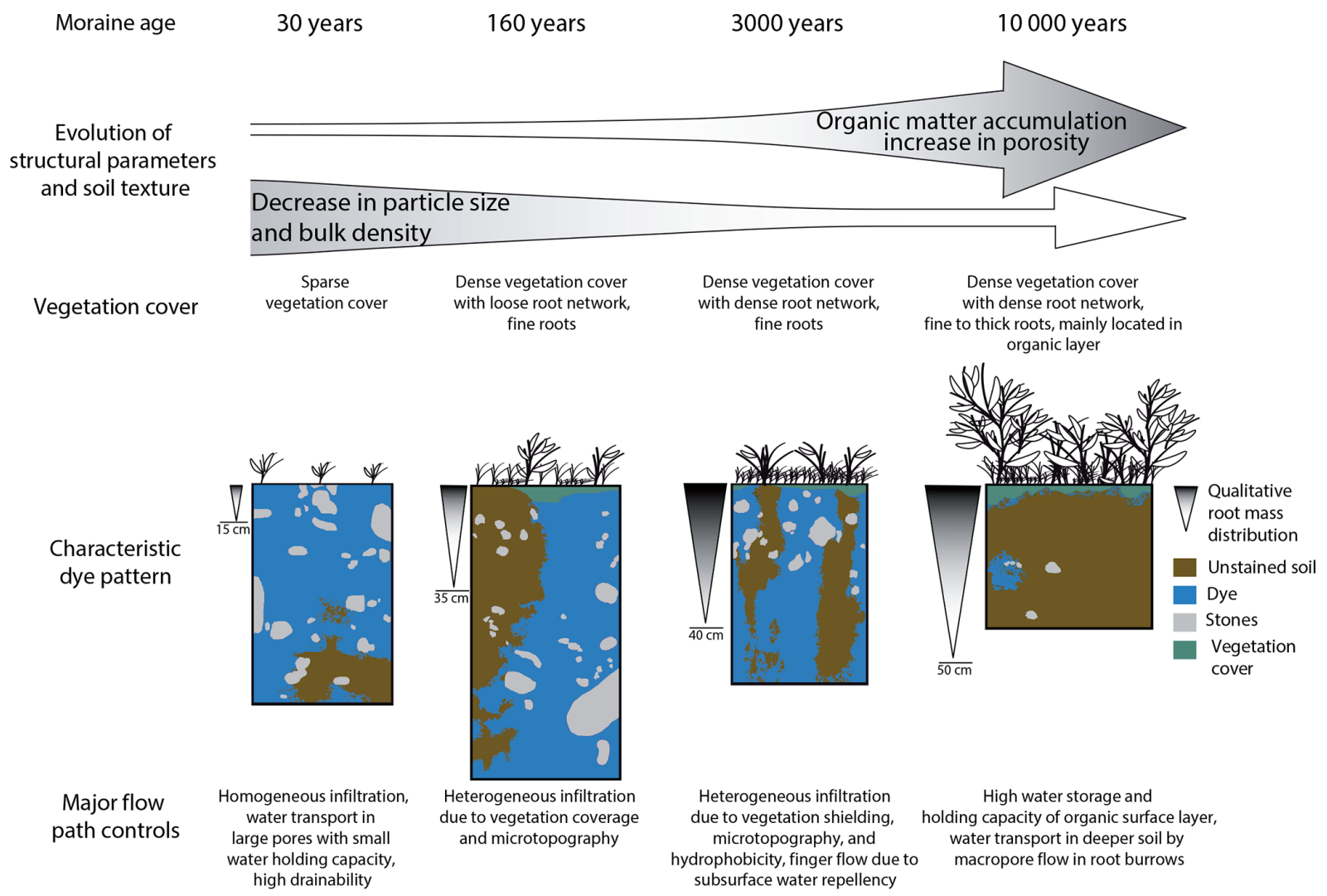

Figure 11. Sequence of observed characteristic dye patterns and derived flow path controls compared to the qualitative evolution of soil texture, structural parameters, and vegetation. The shade of the root mass distribution triangles is a measure for the vertical root mass distribution with a darker color indicating a higher root mass. The width of the triangles is a measure for the root mass comparison between the moraine ages, with broader triangles indicating a higher root mass.

macropores, but especially for the medium-age moraines it seems more controlled by soil surface characteristics such as vegetation patches, microtopography, and hydrophobicity. Thus, the evolution of flow paths is tightly linked to the complex interplay of soil-forming processes and vegetation development over the millennia. A lot of changes in vegetation cover, soil (hydraulic) properties, and flow paths occur within the first 160 years.

It was shown that the complex interaction of vegetation and soil development and its proven effect on flow path development also impacts the water balance, as the storage and conductivity properties of the soil change. However, the interplay between preferential flow paths and the soil hydraulic behavior not only influences the soil water budget but also runoff formation. These findings provide important insights into hydrological flow path evolution in transient systems.

Data availability. The soil physical data are described in detail and can be downloaded from (Hartmann et al., 2020). The Brilliant Blue images and data are available upon request.
Author contributions. AH and ES conducted the field experiments, prepared the images, and performed the analysis. AH collected the soil samples and conducted the laboratory analysis. MW and TB were involved in planning the fieldwork. AH prepared the paper with contributions from all coauthors.

Competing interests. The authors declare that they have no conflict of interest.

Special issue statement. This article is part of the special issue "Linking landscape organisation and hydrological functioning: from hypotheses and observations to concepts, models and understanding (HESS/ESSD inter-journal SI)". It is not associated with a conference.

Acknowledgements. We thank Moritz Lesche and Jonas Freymüller for their assistance in the field. We also thank Kraftwerke Oberhasli AG (KWO) for permission to conduct the experiments. Many thanks to Thomas Michel and his team from the Alpin Center Sustenpass and Peter Luchs for their kind hospitality and support. 
We thank Nicholas Jarvis and one anonymous reviewer for their effort and improving our paper.

Financial support. This research has been supported by the German Research Foundation (DFG) and the Swiss National Science Foundation (SNF) within the DFG-SNF project HILLSCAPE (Hillslope Chronosequence and Process Evolution).

The article processing charges for this open-access publication were covered by a Research

Centre of the Helmholtz Association.

Review statement. This paper was edited by Patricia Saco and reviewed by Nicholas Jarvis and one anonymous referee.

\section{References}

Allaire, S. E., Roulier, S., and Cessna, A. J.: Quantifying preferential flow in soils: A review of different techniques, J. Hydrol., 378, 179-204, https://doi.org/10.1016/j.jhydrol.2009.08.013, 2009.

Amundson, R., Berhe, A. A., Hopmans, J. W., Olson, C., Sztein, A. E., and Sparks, D. L.: Soil and human security in the 21 st century, Science, 348, 1261071, https://doi.org/10.1126/science.1261071, 2015.

Arvidsson, J.: Influence of soil texture and organic matter content on bulk density, air content, compression index and crop yield in field and laboratory compression experiments, Soil Till. Res., 49, 159-170, https://doi.org/10.1016/S0167-1987(98)00164-0, 1998.

Bachmair, S., Weiler, M., and Nützmann, G.: Controls of land use and soil structure on water movement: Lessons for pollutant transfer through the unsaturated zone, J. Hydrol., 369, 241-252, https://doi.org/10.1016/j.jhydrol.2009.02.031, 2009.

Bevington, J., Piragnolo, D., Teatini, P., Vellidis, G., and Morari, F.: On the spatial variability of soil hydraulic properties in a Holocene coastal farmland, Geoderma, 262, 294-305, https://doi.org/10.1016/j.geoderma.2015.08.025, 2016.

Birse, E. L.: Suggested amendments to the world soil classification to accomodate scottish mountain and aeolian soils, J. Soil Sci., 31, 117-124, https://doi.org/10.1111/j.13652389.1980.tb02069.x, 1980.

Blass, A., Anselmetti, F. S., and Ariztegui, D.: 60 years of glaciolacustrine sedimentation in Steinsee (Sustenpass, Switzerland) compared with historic events and instrumental meteorological data, Eclogae Geol. Helv., 96, 59-71, https://doi.org/10.1007/978-3-0348-7992-7_8, 2003.

Blume, T., Zehe, E., and Bronstert, A.: Investigation of runoff generation in a pristine, poorly gauged catchment in the Chilean Andes II: Qualitative and quantitative use of tracers at three spatial scales, Hydrol. Process., 22, 3676-3688, https://doi.org/10.1002/hyp.6970, 2008.

Blume, T., Zehe, E., and Bronstert, A.: Use of soil moisture dynamics and patterns at different spatio-temporal scales for the investigation of subsurface flow processes, Hydrol. Earth Syst. Sci., 13, 1215-1233, https://doi.org/10.5194/hess-13-1215-2009, 2009.
Bogner, C., Wolf, B., Schlather, M., and Huwe, B.: Analysing flow patterns from dye tracer experiments in a forest soil using extreme value statistics, Eur. J. Soil Sci., 59, 103-113, https://doi.org/10.1111/j.1365-2389.2007.00974.x, 2008.

Bogner, C., Bauer, F., y Widemann, B. T., Viñan, P., Balcazar, L., and Huwe, B.: Quantifying the morphology of flow patterns in landslide-affected and unaffected soils, J. Hydrol., 511, 460-473, https://doi.org/10.1016/j.jhydrol.2014.01.063, 2014.

Bundt, M., Albrecht, A., Froidevaux, P., Blaser, P., and Flühler, H.: Impact of Preferential Flow on Radionuclide Distribution in Soil, Environ. Sci. Technol., 34, 3895-3899, https://doi.org/10.1021/es9913636, 2000.

Cammeraat, E. L. H. and Kooijman, A. M.: Biological control of pedological and hydro-geomorphological processes in a deciduous forest ecosystem, Biologia, 64, 428-432, https://doi.org/10.2478/s11756-009-0075-x, 2009.

Carey, S. K., Quinton, W. L., and Goeller, N. T.: Field and laboratory estimates of pore size properties and hydraulic characteristics for subarctic organic soils, Hydrol. Process., 21, 2560-2571, https://doi.org/10.1002/hyp.6795, 2007.

Casagrande, A.: Die Aräometer-Methode zur Bestimmung der Kornverteilung von Böden und anderen Materialien, Springer, Berlin, Heidelberg, 1934.

Cheng, J., Wu, J., Chen, Y., and Zhang, H.: Characteristics of preferential flow paths and their effects on soil properties, Forestry Chron., 90, 192-196, https://doi.org/10.5558/tfc2014-037, 2014.

Clothier, B. E., Green, S. R., and Deurer, M.: Preferential flow and transport in soil: progress and prognosis, Eur. J. Soil Sci., 59, 2-13, https://doi.org/10.1111/j.1365-2389.2007.00991.x, 2008.

Crocker, R. L. and Dickson, B. A.: Soil Development on the Recessional Moraines of the Herbert and Mendenhall Glaciers, SouthEastern Alaska, J. Ecol., 45, 169-185, 1957.

Crocker, R. L. and Major, J.: Soil Development in Relation to Vegetation and Surface Age at Glacier Bay, Alaska, J. Ecol., 43, 427448, 1955.

D’Amico, M. E., Freppaz, M., Filippa, G., and Zanini, E.: Vegetation influence on soil formation rate in a proglacial chronosequence (Lys Glacier, NW Italian Alps), CATENA, 113, 122-137, https://doi.org/10.1016/j.catena.2013.10.001, 2014.

DeBano, L. F.: Water Repellent Soils: A state-of-the-art, NASA STI/Recon Technical Report N, 1981.

Dekker, L. and Ritsema, C.: Wetting patterns and moisture variability in water repellent Dutch soils, J. Hydrol., 231-232, 148-164, https://doi.org/10.1016/S0022-1694(00)00191-8, 2000.

Doerr, S., Shakesby, R., and P.D. Walsh, R.: Spatial Variability of Soil Hydrophobicity in Fire-Prone Eucalyptus and Pine Forests, Portugal, Soil Science, 163, 313-324, https://doi.org/10.1097/00010694-199804000-00006, 1998.

Doerr, S., Shakesby, R., and Walsh, R.: Soil water repellency: its causes, characteristics and hydro-geomorphological significance, Earth-Sci. Rev., 51, 33-65, https://doi.org/10.1016/S00128252(00)00011-8, 2000.

Douglass, D. C. and Bockheim, J. G.: Soil-forming rates and processes on Quaternary moraines near Lago Buenos Aires, Argentina, Quaternary Res., 65, 293-307, https://doi.org/10.1016/j.yqres.2005.08.027, 2006.

Dümig, A., Smittenberg, R., and Kögel-Knabner, I.: Concurrent evolution of organic and mineral components during initial soil development after retreat of the 
Damma glacier, Switzerland, Geoderma, 163, 83-94, https://doi.org/10.1016/j.geoderma.2011.04.006, 2011.

Egli, M., Mavris, C., Mirabella, A., and Giaccai, D.: Soil organic matter formation along a chronosequence in the Morteratsch proglacial area (Upper Engadine, Switzerland), CATENA, 82, 61-69, https://doi.org/10.1016/j.catena.2010.05.001, 2010.

Ellis, S.: Weathering, soils and paleosols edited by I. P. Martini and W. Chesworth, Elsevier, Amsterdam and New York, Earth Surf. Proc. Land., 18, 469-469, https://doi.org/10.1002/esp.3290180508, 1992.

Fukutome, S., Schindler, A., and Capobianco, A.: MeteoSwiss extreme value analyses: User manual and documentation, Technical Report MeteoSwiss, 255, 2 edn., 2017.

Gimbel, K. F., Puhlmann, H., and Weiler, M.: Does drought alter hydrological functions in forest soils?, Hydrol. Earth Syst. Sci., 20, 1301-1317, https://doi.org/10.5194/hess-20-1301-2016, 2016.

Google: Stone Glacier Map, 3863 Gadmen, CH, Google Maps, April 2020, https://www.google.com/maps/search/ Steingletscher/@46.7423569,8.412469,625a,35y,138.98h,77. 9t/data=!3m1!1e3, (Pictures 2020 Flotron/Perinjaquet, Maxar Technologies, Maps), last access: 17 June 2020.

Hardie, M. A., Cotching, W. E., Doyle, R. B., Holz, G., Lisson, S., and Mattern, K.: Effect of antecedent soil moisture on preferential flow in a texture-contrast soil, J. Hydrol., 398, 191-201, https://doi.org/10.1016/j.jhydrol.2010.12.008, 2011.

Hartmann, A., Weiler, M., and Blume, T.: The impact of landscape evolution on soil physics: Evolution of soil physical and hydraulic properties along two chronosequences of proglacial moraines, Earth Syst. Sci. Data Discuss., https://doi.org/10.5194/essd-2020-110, in review, 2020.

Hatfield, J. L., Sauer, T., and M. Cruse, R.: Soil: The Forgotten Piece of the Water, Food, Energy Nexus, Adv. Agron., 143, 146, https://doi.org/10.1016/bs.agron.2017.02.001, 2017.

He, L. and Tang, Y.: Soil development along primary succession sequences on moraines of Hailuogou Glacier, Gongga Mountain, Sichuan, China, CATENA, 72, 259-269, https://doi.org/10.1016/j.catena.2007.05.010, 2008.

Heikkinen, O. and Fogelberg, P.: Bodenentwicklung im Hochgebirge : ein Beispiel vom Vorfeld des Steingletschers in der Schweiz, Geogr. Helv., 35, 107-112, https://doi.org/10.5194/gh35-107-1980, 1980.

Hendrickx, J. M. H. and Flury, M.: Uniform and Preferential Flow Mechanisms in the Vadose Zone, in: Conceptual Models of Flow and Transport in the Fractured Vadose Zone, National Research Council, National Academy Press, Washington, DC, 149-187, 2001.

Hu, W., Shao, M. A., Wang, Q. J., Fan, J., and Reichardt, K.: Spatial variability of soil hydraulic properties on a steep slope in the loess plateau of China, Sci. Agr., 65, 268-276, 2008.

Jarvis, N., Moeys, J., Koestel, J., and Hollis, J.: Preferential flow in a pedological perspective, in: Hydropedology: synergistic integration of soil science and hydrology, edited by: Lin, H., Academic Press, Elsevier B.V., 75-120, 2012.

Jarvis, N. J.: A review of non-equilibrium water flow and solute transport in soil macropores: principles, controlling factors and consequences for water quality, Eur. J. Soil Sci., 58, 523-546, https://doi.org/10.1111/j.1365-2389.2007.00915.x, 2007.

Jin, L. and Brantley, S. L.: Soil chemistry and shale weathering on a hillslope influenced by convergent hydro- logic flow regime at the Susquehanna/Shale Hills Critical Zone Observatory, Appl. Geochem., 26, S51-S56, https://doi.org/10.1016/j.apgeochem.2011.03.027, 2011.

Laine-Kaulio, H., Backnäs, S., Koivusalo, H., and Laurén, A.: Dye tracer visualization of flow patterns and pathways in glacial sandy till at a boreal forest hillslope, Geoderma, 259-260, 2334, https://doi.org/10.1016/j.geoderma.2015.05.004, 2015.

Lin, H.: Hydropedology: Bridging Disciplines, Scales, and Data, Vadose Zone J., 2, 1-11, https://doi.org/10.2113/2.1.1, 2003.

Lohse, K. A. and Dietrich, W. E.: Contrasting effects of soil development on hydrological properties and flow paths, Water Resour. Res., 41, https://doi.org/10.1029/2004WR003403, 2005.

Maier, F., van Meerveld, I., Greinwald, K., Gebauer, T., Lustenberger, F., Hartmann, A., and Musso, A.: Effects of soil and vegetation development on surface hydrological properties of moraines in the Swiss Alps, CATENA, 187, 104353, https://doi.org/10.1016/j.catena.2019.104353, 2019.

Mooney, S. J. and Morris, C.: A morphological approach to understanding preferential flow using image analysis with dye tracers and X-ray Computed Tomography, CATENA, 73, 204-211, https://doi.org/10.1016/j.catena.2007.09.003, 2008.

Musso, A., Lamorski, K., Sławiński, C., Geitner, C., Hunt, A., Greinwald, K., and Egli, M.: Evolution of soil pores and their characteristics in a siliceous and calcareous proglacial area, CATENA, 182, 104154, https://doi.org/10.1016/j.catena.2019.104154, 2019.

Neris, J., Jiménez, C., Fuentes, J., Morillas, G., and Tejedor, M.: Vegetation and land-use effects on soil properties and water infiltration of Andisols in Tenerife (Canary Islands, Spain), CATENA, 98, 55-62, https://doi.org/10.1016/j.catena.2012.06.006, 2012.

Nyberg, L.: Water flow path interactions with soil hydraulic properties in till soil at Gårdsjön, Sweden, J. Hydrol., 170, 255-275, https://doi.org/10.1016/0022-1694(94)02667-Z, 1995.

Öhrström, P., Persson, M., Albergel, J., Zante, P., Nasri, S., Berndtsson, R., and Olsson, J.: Field-scale variation of preferential flow as indicated from dye coverage, J. Hydrol., 257, 164-173, https://doi.org/10.1016/S0022-1694(01)00537-6, 2002.

Quisenberry, V., Smith, B., Phillips, R., Scott, H., and Nortcliff, S.: A Soil Classification System for Describing Water and Chemical Transport, Soil Sci., 156, 306-315 https://doi.org/10.1097/00010694-199311000-00003, 1993.

Reeder, C. J. and Jurgensen, M.: Fire-induced water repellency in forest soils of upper Michigan, Can. J. Forest Res., 9, 369-373, https://doi.org/10.1139/x79-062, 1979.

Richter, D. D. and Mobley, M. L.: Monitoring Earth's Critical Zone, Science, 326, 1067-1068, https://doi.org/10.1126/science.1179117, 2009.

Ritsema, C. J. and Dekker, L. W.: How water moves in a water repellent sandy soil: 2. Dynamics of fingered flow, Water Resour Res., 30, 2519-2531, https://doi.org/10.1029/94wr00750, 1994.

Rye, C. and Smettem, K.: The effect of water repellent soil surface layers on preferential flow and bare soil evaporation, Geoderma, 289, 142-149, https://doi.org/10.1016/j.geoderma.2016.11.032, 2017.

Schimmelpfennig, I., Schaefer, J. M., Akçar, N., Koffman, T., Ivy-Ochs, S., Schwartz, R., Finkel, R. C., Zimmerman, S., and Schlüchter, C.: A chronology of Holocene and Little Ice Age glacier culminations of the Steingletscher, Cen- 
tral Alps, Switzerland, based on high-sensitivity beryllium10 moraine dating, Earth Planet. Sc. Lett., 393, 220-230, https://doi.org/10.1016/j.eps1.2014.02.046, 2014.

Schweizerische Eidgenossenschaft: Klimanormwerte Grimsel Hospiz Normperiode 1981-2010, Bundesamt für Meteorologie und Klimatologie MeteoSchweiz, available at: https://www.meteoschweiz.admin.ch/home/ klima/schweizer-klima-im-detail/klima-normwerte/

klimadiagramme-und-normwerte-pro-station.html?region=

Tabelle (last access: 17 June 2020), 2016.

Shang, J., Zhu, Q., and Zhang, W.: Advancing Soil Physics for Securing Food, Water, Soil and Ecosystem Services, Vadose Zone J., 17, 180207, https://doi.org/10.2136/vzj2018.11.0207, 2018.

Tillman, R. W., Scotter, D. R., Wallis, M. G., and Clothier, B. E.: Water repellency and its measurement by using intrinsic sorptivity, Soil Res., 27, 637-644, https://doi.org/10.1071/SR9890637, 1989.

van Schaik, N.: Spatial variability of infiltration patterns related to site characteristics in a semi-arid watershed, CATENA, 78, 3647, https://doi.org/10.1016/j.catena.2009.02.017, 2009.

Vilmundardóttir, O. K., Gísladóttir, G., and Lal, R.: Early stage development of selected soil properties along the proglacial moraines of Skaftafellsjökull glacier, SE-Iceland, CATENA, 121, 142-150, https://doi.org/10.1016/j.catena.2014.04.020, 2014.

Wallach, R. and Jortzick, C.: Unstable finger-like flow in water-repellent soils during wetting and drainage - The case of a point water source, J. Hydrol., 351, 26-41, https://doi.org/10.1016/j.jhydrol.2007.11.032, 2008.
Wang, Y., Li, Y., Wang, X., and Chau, H. W.: Finger Flow Development in Layered Water-Repellent Soils, Vadose Zone J., 17, 170171, https://doi.org/10.2136/vzj2017.09.0171, 2018.

Weibel, E. R.: Stereological Methods, Vol. 1, in: Practical Methods for Biological Morphometry, Academic Press, London, 21, 630630, https://doi.org/10.1002/jobm.19810210824, 1979.

Weiler, M.: Mechanisms controlling macropore flow during infiltration dye tracer experiments and simulations, $\mathrm{PhD}$ thesis, Swiss Federal Institute of Technology Zurich, https://doi.org/10.3929/ethz-a-004180115, 2001.

Weiler, M. and Flühler, H.: Inferring flow types from dye patterns in macroporous soils, Geoderma, 120, 137-153, https://doi.org/10.1016/j.geoderma.2003.08.014, 2004.

Weiler, M. and Naef, F.: An experimental tracer study of the role of macropores in infiltration in grassland soils, Hydrol. Process., 17, 477-493, https://doi.org/10.1002/hyp.1136, 2003.

Yoshida, T. and Troch, P. A.: Coevolution of volcanic catchments in Japan, Hydrol. Earth Syst. Sci., 20, 1133-1150, https://doi.org/10.5194/hess-20-1133-2016, 2016. 